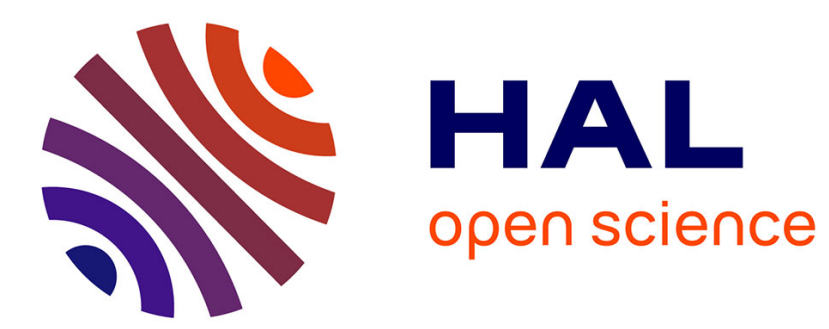

\title{
INFLUENCE OF LOADING RATE ON THE TRANSITION BEHAVIOUR OF STRUCTURAL STEELS
}

J. Falk, W. Dahl

\section{- To cite this version:}

J. Falk, W. Dahl. INFLUENCE OF LOADING RATE ON THE TRANSITION BEHAVIOUR OF STRUCTURAL STEELS. Journal de Physique IV Proceedings, 1991, 01 (C3), pp.C3-613-C3-621. 10.1051/jp4:1991386 . jpa-00250531

\section{HAL Id: jpa-00250531 https://hal.science/jpa-00250531}

Submitted on 1 Jan 1991

HAL is a multi-disciplinary open access archive for the deposit and dissemination of scientific research documents, whether they are published or not. The documents may come from teaching and research institutions in France or abroad, or from public or private research centers.
L'archive ouverte pluridisciplinaire HAL, est destinée au dépôt et à la diffusion de documents scientifiques de niveau recherche, publiés ou non, émanant des établissements d'enseignement et de recherche français ou étrangers, des laboratoires publics ou privés. 
Colloque C3, suppl. au Journal de Physique III, Vol. 1, octobre 1991

\section{INFLUENCE OF LOADING RATE ON THE TRANSITION BEHAVIOUR OF STRUCTURAL STEELS}

J. FALK and W. DAHL

Institut für Eisenhüttenkunde, RWTH Aachen, Intzestr. 1, 5100 Aachen, Germany

\section{Abstract}

The influence of loading rate on the transition temperature $T_{i}$ of different steels with yield strength between $170 \mathrm{MPa}$ and $600 \mathrm{MPa}$ were investigated. The effect of loading rate on $\mathrm{T}_{i}$ was discussed and a model for determining the transition temperature $T_{i}$ by the results of tension tests was presented.

\section{Introduction}

In earlier publication /1/ it was shown that the temperature shift of a transition temperature $\mathrm{T}_{70}$ with higher loading rates could be described with the relative strain rate sensitivity of a yield strength. $\mathrm{T}_{70}$ is the temperature, where the quasistatic $\mathrm{K}_{I C}-\mathrm{T}$-curve reaches the $\mathrm{K}_{\text {Ic }}$-value of $70 \mathrm{MPa} \sqrt{\mathrm{m}}$. In the present work further investigations of the description of the temperature shift of $\mathrm{T}_{i}$ will be presented.

\section{Testmaterials}

The chemical compositions and heat treatments of the steels investigated are shown in table 1 .

The Fe 510 (CaSi) steel has a lower sulfur content and a more globular type of inclusions. The $\mathrm{C} 10$ steel has a coarse grained microstructure $(d=50 \mu \mathrm{m})$ due to annealing at $1200^{\circ} \mathrm{C}$ for a period of 5 hours. 


\section{Experimental techniques}

The tension tests and fracture mechanics tests were performed on a servohydraulic testing machine at ram speeds between $0,02 \mathrm{~mm} / \mathrm{s}$ and $3500 \mathrm{~mm} / \mathrm{s}$. In the fracture mechanics tests at maximum ram speed of $3500 \mathrm{~mm} / \mathrm{s}$ the force was measured by strain gauges fixed on the outer faces of the CT-specimens opposite the crack tip. The load line displacement was measured using a non-contact measuring device working system on the principle of eddy current losses. The experimental set-up is described detailly in earlier publications $/ 2,3 /$.

\begin{tabular}{|c|c|c|c|c|c|c|c|c|c|c|c|c|c|}
\hline \multirow{2}{*}{ Material } & \multirow{2}{*}{ Process } & \multicolumn{1}{|l|}{ Content (wt\%) } \\
\cline { 2 - 20 } & & C & Si & Mn & P & S & Al & Ni & Cu & V & Mo & Cr & Nb \\
\hline 20MnMoNi55 & I & 0.20 & 0.24 & 1.38 & 0.011 & 0.005 & 0.068 & 0.52 & - & - & 0.30 & 0.06 & 0.032 \\
\hline 15NiCuMoNb & I & 0.17 & 0.28 & 0.92 & 0.009 & 0.001 & 0.022 & 1.22 & 0.64 & 0.001 & 0.53 & 0.27 & - \\
\hline Fe510(CaSi) & II & 0.20 & 0.46 & 1.43 & 0.017 & 0.001 & 0.037 & 0.03 & 0.06 & 0.002 & 0.01 & 0.05 & - \\
\hline C10 & III & 0.09 & 0.19 & 0.37 & 0.027 & 0.025 & 0.003 & 0.03 & 0.03 & 0.010 & - & 0.05 & - \\
\hline
\end{tabular}

I - quenched and tempered; II - normalized; III - annealed at $1200^{\circ} \mathrm{C}(5 \mathrm{~h})$ normalized

Table 1: Chemical compositions and heat treatments of the steels investigated

\section{Experiments:}

The fracture mechanics tests were performed at the four ram speeds $0,02 \mathrm{~mm} / \mathrm{s}, 2 \mathrm{~mm} / \mathrm{s}, 500 \mathrm{~mm} / \mathrm{s}$ and $3500 \mathrm{~mm} / \mathrm{s}$. The test temperatures were in the transition region of cleavage to ductile fracture. J-Integral was calculated according to EGF P1-90/4/.

The transition temperature $T_{i}$ was determined as the temperature, where the $\mathrm{J}$-T-curve reached $\mathrm{J}_{i}$. 


\section{Results:}

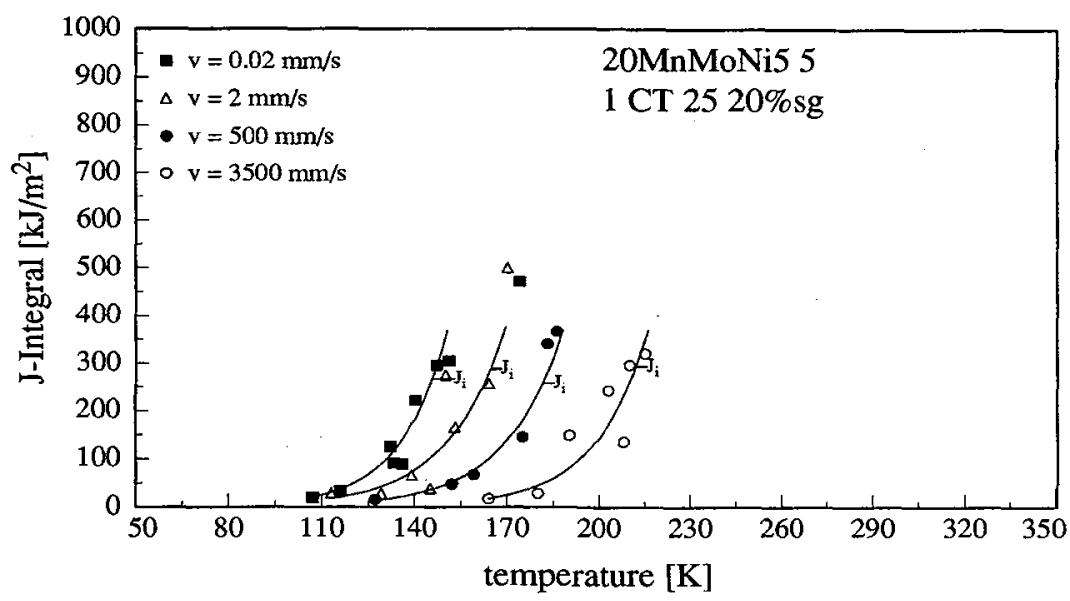

Figure 1: J-T-curve of the 20 MnMoNi 5.5 with determined $\mathrm{T}_{\mathbf{i}}$

Figure 1 presents the J-T-curves of the 20 MnMoNi 55 for four different ram speeds. The transition temperatur $T_{i}$ is shifted from $145 \mathrm{~K}$ to $212 \mathrm{~K}$ by the increasing ram speed from $0,02 \mathrm{~mm} / \mathrm{s}$ to $3500 \mathrm{~mm} / \mathrm{s}$.

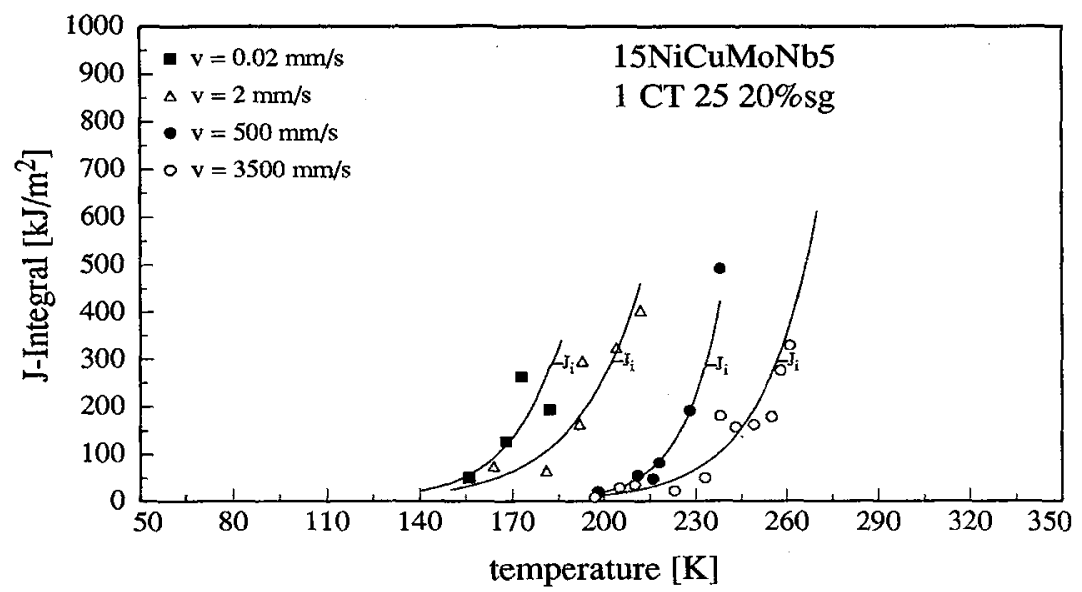

Figure 2: J-T-curves of the 15 NiCuMoNb 5 with determined $\mathrm{T}_{i}$. 


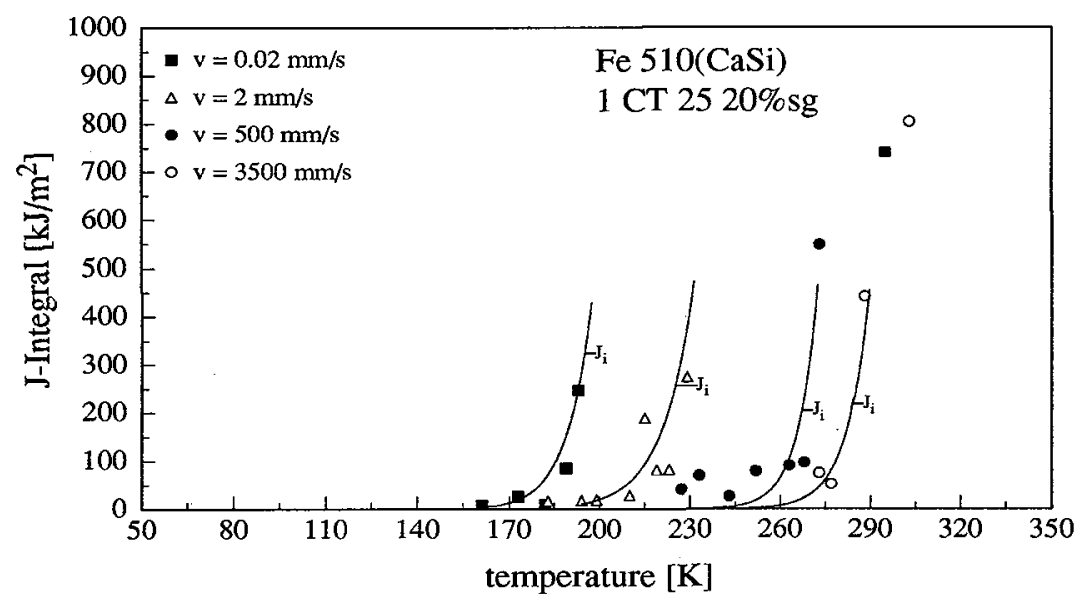

Figure 3: J-T-curves of the Fe 510 (CaSi) with determined $T_{i}$

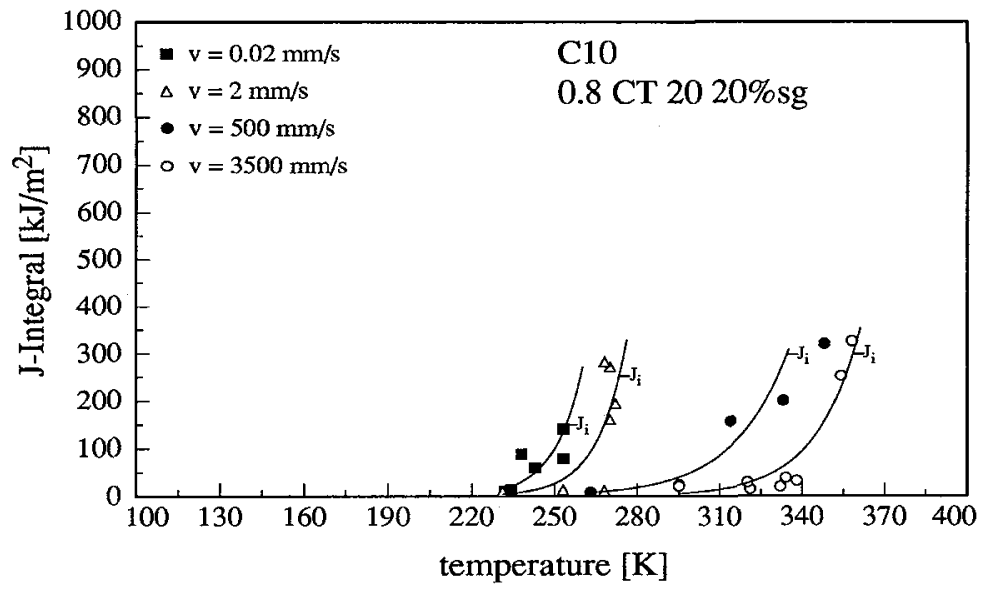

Figure 4: J-T-curves of the C10 with determined $T_{i}$

In the Figures 2-4 the determined J-T-curves for the steels 15 NiCuMoNb 5, Fe 510 (CaSi) und C10 are plotted.

The temperature shift of $T_{i}$ from the ram speed of $0,02 \mathrm{~mm} / \mathrm{s}$ to the ram speed of $3500 \mathrm{~mm} / \mathrm{s}$ is for the $15 \mathrm{NiCuMoNb} 574 \mathrm{~K}$, for the $\mathrm{Fe} 510$ (CaSi) $89 \mathrm{~K}$ and for the $\mathrm{Cl} 0104 \mathrm{~K}$.

It is obvious that the value of the temperature shift depends on the strength of the material. 
In earlier publication $/ 1 /$ a correlation was proposed between the temperature shift $\Delta T$ and the relative strain rate sensitivity of the yield strength $\mathrm{m}_{r}$, which is defined as:

$\mathrm{m}_{r}=\frac{\partial \sigma_{0}}{\sigma_{0} \ln \dot{\varepsilon}}=\frac{\partial \ln \sigma_{0}}{\partial \ln \dot{\varepsilon}}=\frac{\mathrm{m} \cdot \sigma_{0}^{*} \cdot \mathrm{k} \cdot \mathrm{T}}{\Delta \mathrm{G}_{0} \cdot \sigma_{0}} \cdot\left[1-\frac{\mathrm{k} \cdot \mathrm{T} \cdot \ln \dot{\varepsilon}_{\mathrm{O}} / \dot{\varepsilon}}{\Delta \mathrm{G}_{0}}\right]$

$\sigma_{0}$ is the yield stress at the beginning of strain hardening for example $\mathrm{R}_{\mathrm{p} 2,0^{\circ}} \mathrm{m}, \sigma_{0^{*}}^{*} \dot{\varepsilon}$ and $\sigma_{i}$ are shown in table 2 .

\begin{tabular}{|c|c|c|c|c|}
\hline material & $\begin{array}{c}\dot{\varepsilon}_{0} \\
{\left[s^{-1}\right]}\end{array}$ & $\begin{array}{c}\sigma_{i} \\
{[\mathrm{MPa}]}\end{array}$ & $\begin{array}{c}\sigma_{0}^{*} \\
{[\mathrm{MPa}]}\end{array}$ & $\mathrm{m}$ \\
\hline 20NiniMoNi55 & $10^{8}$ & 534 & 744 & 2.65 \\
\hline 15NiCuMoNb5 & $10^{10}$ & 571 & 790 & 2.87 \\
\hline Fe510 (CaSi) & $10^{8}$ & 382 & 761 & 2.84 \\
\hline C10 & $10^{8}$ & 166 & 967 & 2.71 \\
\hline
\end{tabular}

Table 2: Constants $\sigma_{0}^{*}, \dot{\varepsilon}_{0}$ and $\sigma_{i}$ and $m$ for the description of the temperature and strain rate dependence of the lower yield strength $\mathrm{R}_{\text {eL }}$

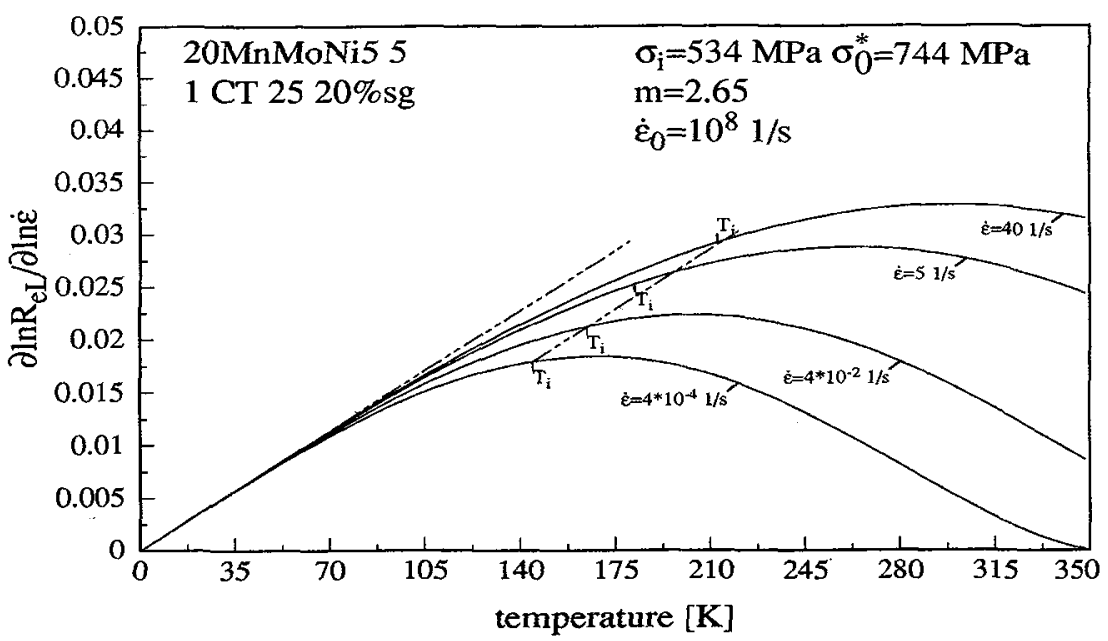

Figure 5: $m_{r}$-T-curve for the lower yield strength of the 20 MnMoNi 55 
In Figure 5 the relative strain rate sensitivity of the lower yield strength for the four loading rates of the $20 \mathrm{MnMoNi} 55$ is plotted versus temperature. Furthermore the determined transition temperatures $T_{i}$ for the different loading rates are marked.

It was found, that the temperatures $T_{i}$ at the different loading rates are parallel to a straight line at the beginning of the $\mathrm{m}_{r}$-T-curve. Determining the transition temperature $T_{i}$ for any loading rate in the investigated strain rate range by the results of tension tests the knowledge of the following points is necessary:

1) the strain rate and temperature dependence of a yield strength of the steel.

2) the transition temperature $T_{i}$ for one loading rate.

Then a parallel to the straight line in the beginning of the $\mathrm{m}_{r}-\mathrm{T}-$ curve must be drawn through the temperature $\mathrm{T}_{i}$ at one loading rate and the intersection points of this parallel with the $m_{r}-\mathrm{T}$-curve for an other loading rate give the temperature $\mathrm{T}_{i}$ for this loading rate.

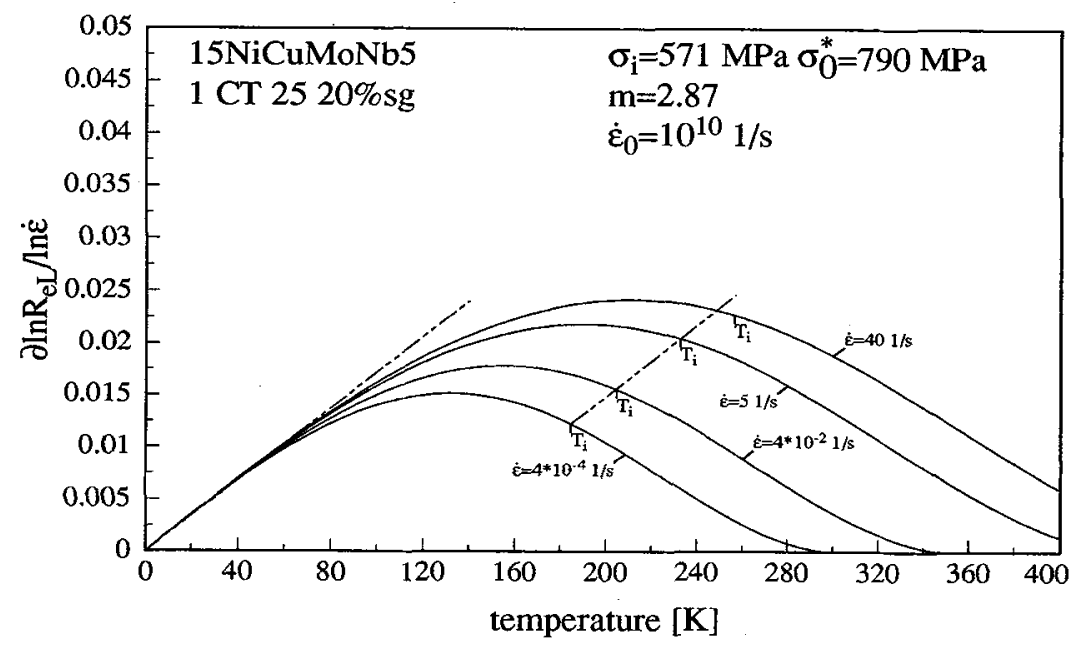

Figure 6: $m_{r}-T$-curve for the lower yield strength of the $15 \mathrm{NiCuMONb} 5$ 


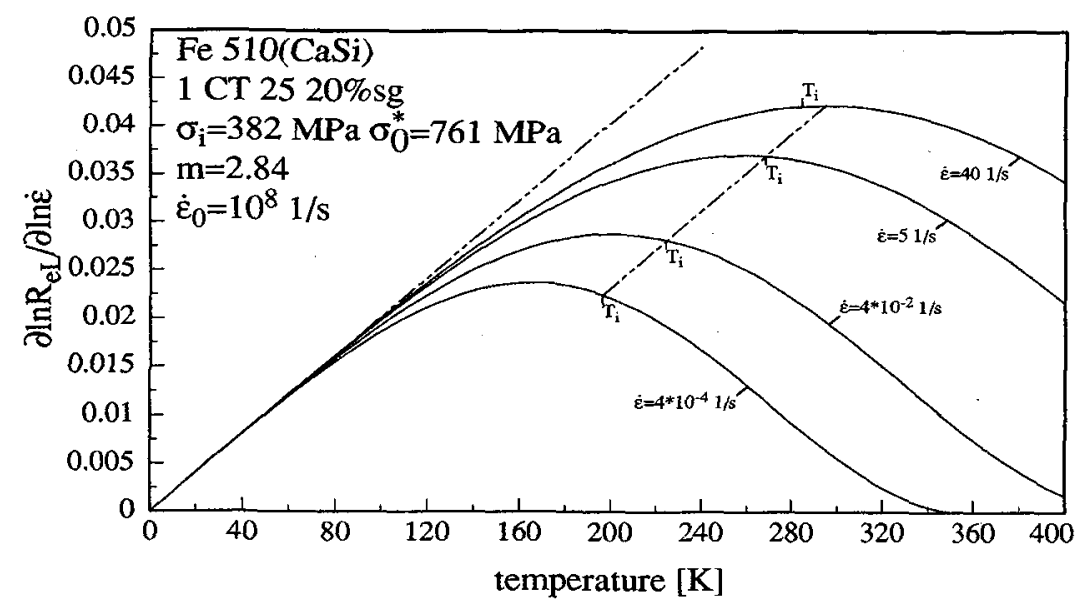

Figure 7: $m_{r}$-T-curve for the lower yield strength of the Fe 510 (Casi)

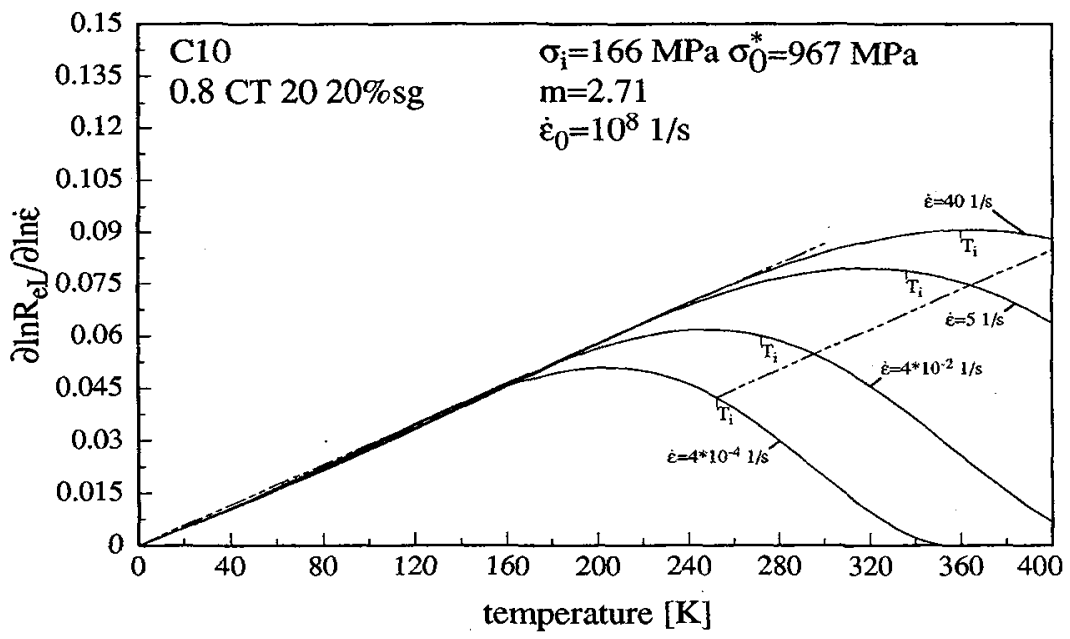

Figure 8: $m_{Y}-T$-curve for the lower yield strength of the c10

Figures 6-8 present the $m_{r}-T$-curves for the lower yield strength with the determined $T_{i}$ of the other investigated steels. It becomes clear that also for this steels the transition temperature $T_{i}$ from the experiments can be determined by this method. 


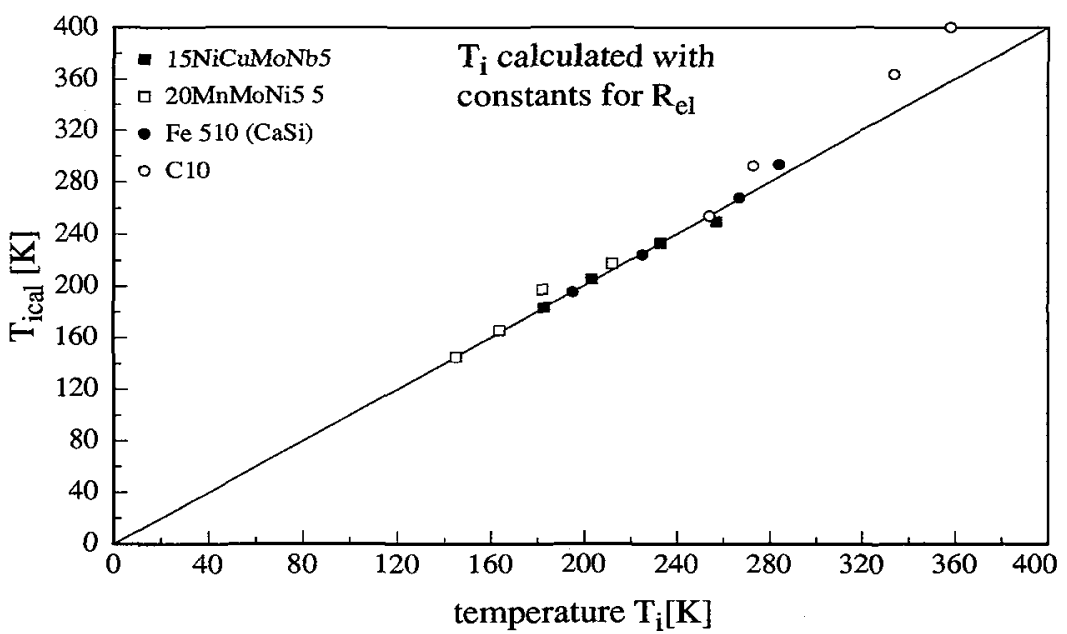

Figure 9: Calculated $T_{i}$-values versus determined $T_{i}$-values by fracture mechanics tests.

In Figure 9 the $T_{i}$-values determined with the method mentioned before are plotted versus the $\mathrm{T}_{i}$-values from fracture mechanics tests at different loading rates.

For the three steels 20 MnMoNi 5 5, 15 NiCuMoNb 5 and Fe 510 (Casi) the prediction of $T_{i}$ with the proposed method is quite good.

only for the clo the prediction of the transition temperature $\mathrm{T}_{i}$ is not so good as for the other steels. This is probably caused by the temperature $\mathrm{T}_{i}$ at quasistatic loading, which seems not to be correct, because the other 3 transition temperature are nearly on a straight Iine.

\section{Summary}

Fracture mechanics tests were performed at four different loading rates for the steels 20 MnMoNi 5 , 15 NiCuMoNb 5, Fe 510 (Casi) and C10 in the transition areas temperature from cleavage to ductile fracture. The transition temperature $T_{i}$ was determined.

With higher loading rates the transition temperature was shifted up to higher temperatures. The transition temperature $T_{i}$ at higher loading rates could be predicted by knowledge of the strain rate and temperature dependence of a yield strength at the beginning of strain hardening based on the model of thermally activated yielding and a transition temperature $\mathrm{T}_{i}$ at one loading rate. 
It seems to be important that the constants $\sigma_{i}, \sigma_{0}^{*}$, m and $\dot{\varepsilon}_{0}$ are determined with a high statistic certainty because mistakes at the determination of this constants propagate in the precision of the prediction of $T_{i}$. Further investigations should be done especially with steels with a larger range of strength levels.

\section{References}

11/ Brüninghaus, K.; Hesse, W.; Twickler, M. u. Dahl W.: Impact 87, DGM-Informationsgesellschaft, pp. 121-128

12/ Brüninghaus, K.; Twickler, M.; Twickler, R. u. Dahl w.: Dymat 88, Ajaccio 1988, Journal de Physique, Colloque $C 3$, Supplément au $\mathrm{n}^{\circ} 9,49(1988)$, pp. C3-301-306

/3/ Brüninghaus, K.; Falk, J.; Twickler, M. u. Dahl W.: to be published in Nucl. Eng. and Design

14/ EGF Recommendations P1-90 for Determining the Fracture Resistance of Ductile Materials, December 1989 